\title{
Protective value of synovial cysts in rheumatoid knees
}

\author{
G. R. GENOVESE, ${ }^{*}$ M. I. V. JAYSON, ${ }^{*}$ AND A. ST. J. DIXON*
}

From the Royal National Hospital for Rheumatic Diseases, Bath, and the Department of Medicine, Bristol Royal Infirmary

Subatmospheric or small positive pressures occur within the normal knee during walking (Dixon, 1966; Jayson and Dixon, 1970a). However, in the presence of rheumatoid arthritis and an effusion, very high positive pressures are produced. It has been shown that a synovial cyst reduces the volume of effusion within the rheumatoid knee by means of its valvular connection (Jayson and Dixon, 1970b). This limits the increase of intra-articular pressure and should therefore protect the knee against pressure damage. We have tested this hypothesis by relating the radiological evidence of damage to the knee to the size of associated synovial cysts.

\section{Subjects studied}

A series of 24 patients (17 females and 7 males) with definite or classical rheumatoid arthritis (Ropes, Bennett, Cobb, Jacox, and Jessar, 1959) affecting one or both knees for at least 5 years were randomly chosen from those admitted to the Royal National Hospital for Rheumatic Diseases during the period October, 1970, to January, 1971 inclusive. Twelve had both knees involved, giving a total of 36 knees studied.

\section{Methods}

All patients were examined carefully for popliteal cysts. The range of flexion of the knee and lateral instability were measured with a goniometer. Standing knee radiographs were taken, followed by arthrograms performed by aspirating any effusion present, injecting $20 \mathrm{ml}$. of 60 per cent. megalumine iothalamate (Conray 280 ) and $x$ raying before and after 5 minutes exercise. The distance between the $x$ ray tube and the knee was kept constant.

Without knowledge of the clinical and arthrographic findings, the plain knee radiographs were read simultaneously by two of the authors (M. I. V.J. and A.St. J.D.) and then re-read 1 week later in order to minimize observer error. Seven features were looked at: osteoporosis, osteophytes, surface erosions, geodes (bone cysts), and loss of joint space in the patello-femoral, medial, and lateral tibial-femoral compartments. The observations were scored as follows: 0 , normal; 1 , possible change; 2 , definite change; 3 , severe change. A 'total knee score' was calculated for each joint by adding up the various scores from the two separate readings. The maximum score for each of the seven features was therefore six, and for the 'total knee score' 42.

The third author (G. R. G.) independently measured the areas projected by the synovial cysts in the lateral knee arthrograms using a millimetre grid on which the films were superimposed.

\section{Results}

In 35 of the 36 films the contrast medium extended from the strict anatomical limits of the knee joint into or beyond the popliteal space. The cyst shadow areas varied from 0.5 to $26 \mathrm{sq}$. $\mathrm{cm}$. The majority measured 1 to 6 sq. $\mathrm{cm}$. and lay medially and probably represented communications between the joint and the various bursae behind the knee. Ten knees showed cyst shadows greater in size than $6 \mathrm{sq} . \mathrm{cm}$. Three of these cysts extended into the calf. Six had not been detected clinically, including the largest, the shadow of which measured $26 \mathrm{sq}$. cm. (Fig. 1, overleaf).

A significant inverse relationship was found between the 'total knee score' and the area of the synovial cyst shadow (Fig. 2). Analyses were made comparing the cysts with the elements making up the 'total knee score'. The only interesting finding was that knees with large geodes were associated with small cysts only, whereas knees with small geodes were associated with a wide range of cyst sizes (Fig. 3 ).

The knees showing lateral instability had significantly larger cysts than those without instability (Fig. 4). Patients receiving corticosteroids did not differ from those not receiving corticosteroids with regard to cyst size and lateral instability. The length of time the knee had been affected by rheumatoid arthritis was not significantly correlated with the 'total knee score' or the size of the synovial cyst. 


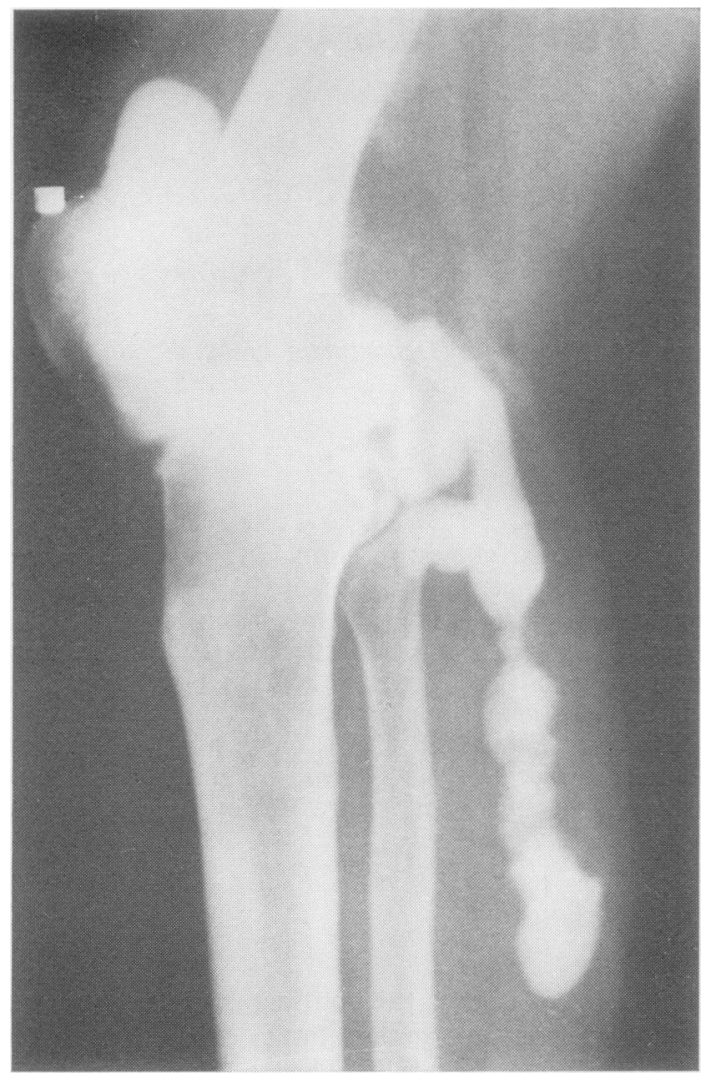

FIG. 1 Lateral knee arthrogram of the patient with the largest synovial cyst. This had not been detected clinically

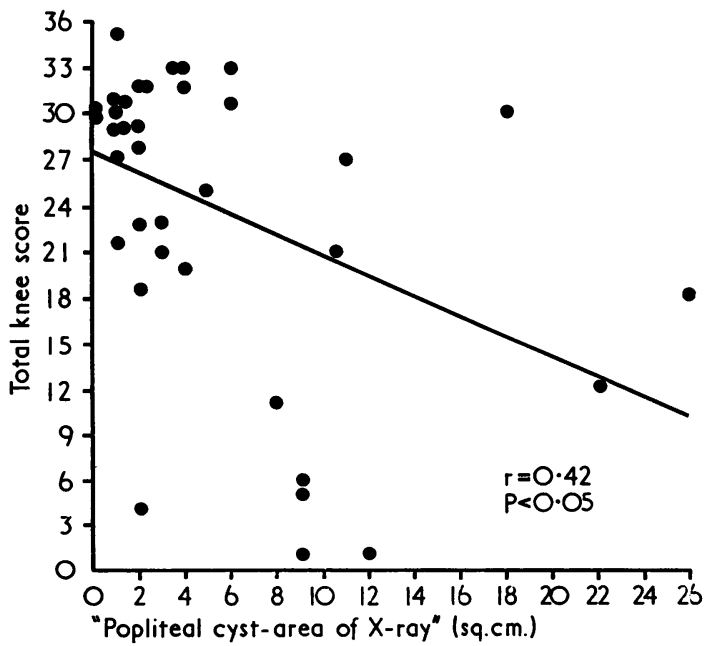

FIG. 2 Inverse relationship between sizes of synovial cysts and 'total knee score'

\section{Discussion}

Popliteal cysts are thought to occur as herniations of synovial fluid through the posterior wall of the joint

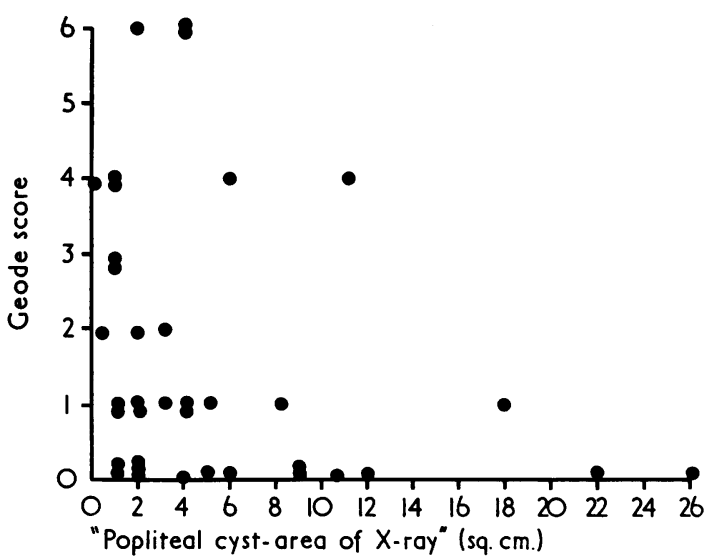

FIG. 3 Relationship between geodes and synovial cysts

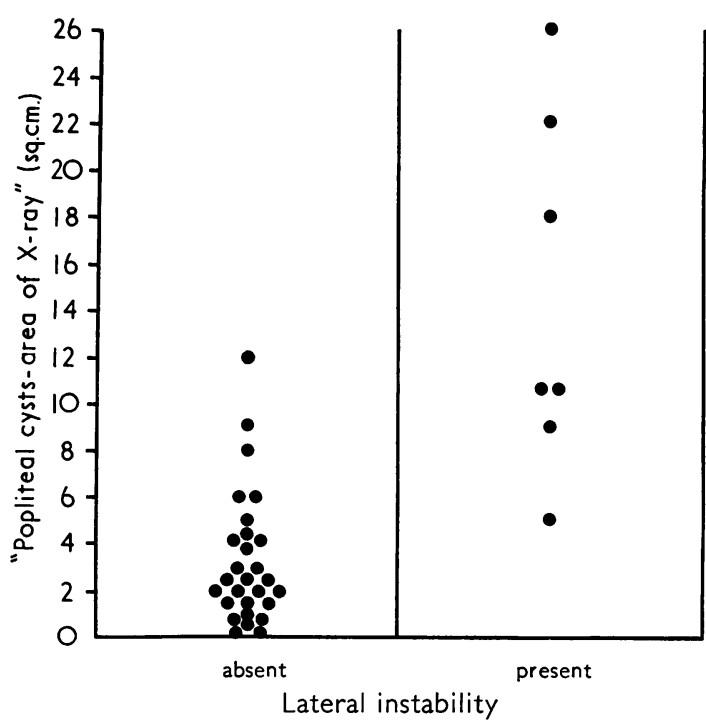

FIG. 4 Comparison of synovial cyst sizes in knees with and without lateral instability. $t=4.09 ; \mathrm{P}<0.0001$

capsule (Billroth, 1875; Lewin, 1952; Palmer, 1969), or as distensions of communicating gastrocnemius/ semimembranosus bursae (Fullerton, 1916; Wilson, Eyre-Brook, and Francis, 1938; Harvey and Corcos, 1960; Gristina and Wilson, 1964), or as a result of both these mechanisms (Meyerding and Van Demark, 1943; Burleson, Bickel, and Dahlin, 1956; Kogstad, 1965; Perri, Rodnan, and Mankin, 1968). The frequency with which synovial cysts complicate rheumatoid knees is difficult to ascertain since they are aften symptomless (Hall and Scott, 1966) or undetectable clinically (Palmer, 1969). Kogstad (1965) calculated that they occurred in only 3 per cent. of his rheumatoid patients. The present survey indicates that they are common in patients whose knees have been affected by rheumatoid arthritis for 
at least 5 years. Some extension behind the knee was present in all but one, and large cysts were found in ten of the 36 knees. It is of particular importance that six of these large cysts were not detected clinically even when the knees had been specifically examined for their presence.

It has been suggested that corticosteroids weaken the supporting tissues so that popliteal cysts develop (Litwin, Lister, and Rotstein, 1964). However, as far as acute joint rupture is concerned, corticosteroids were not thought to be an important factor (Jayson, Swannell, Kirk, and Dixon, 1969). In the present study, corticosteroids could not be incriminated as causing larger cysts. Lateral knee instability is due to weakness of the medial and lateral ligaments, but was not found to be more common in those who had received corticosteroids. Unstable knees were, however, shown to be associated with larger synovial cysts (Fig. 4).

The rise of intra-articular pressure on use of a joint is directly related to the volume of effusion within it (Jayson and Dixon, 1970a). Jayson and Dixon (1970b) have shown that popliteal cysts are joined to the knee by valvular connections which allow fluid to pass out of the knee into the cyst and thus significantly reduce the volume of effusion within the joint space. Cysts therefore limit any rise of pressure on use of the knee and should protect the joint against the damage produced by high pressures. We have been able to demonstrate an inverse correlation between synovial cysts and 'total knee score'. Similarly, knees with extensive geodes were associated with small synovial cysts, while those with minimal or no geodes were associated with cysts of a wide range of sizes. In some of these the minimal geodes and cysts could simply be due to the mildness of arthritis. In the knees with large synovial cysts we postulate that the cysts provided protection against joint damage.

Opinions vary concerning the aetiology of geodes. Fletcher and Rowley (1952) and Soila (1963) thought that they were not connected with the surface of the bone, but were formed by destruction of the subcortical bone because of nutritional, vascular, or metabolic deficiencies. Others have shown a connection with the joint (Freund, 1940; Cruickshank, Macleod and Shaerer, 1954; Bywaters, 1964; Kersley,
Ross, Fowles, and Johnson, 1964; Jayson, Rubenstein, and Dixon, 1970). Castillo, El Sallab, and Scott (1965) and Jayson and others (1970) have suggested that geodes develop because of the increase of intraarticular pressure on use of a joint. Normal articular bone is strong enough to withstand these pressures but where it is weakened by periarticular osteoporosis or where articular cartilage is eroded by granulation tissue the synovial fluid when under high pressure can readily burst through.

It has been suggested that the pressure in the bone marrow exceeds that in the joint space during use of the joint and is important for the flow of nutrition to cartilage (Inglemark and Ekholm, 1948; Inglemark and Saaf, 1948; Ekholm and Inglemark, 1952; Greenwald and Haynes, 1969). The increased intraarticular pressures of rheumatoid arthritis and of synovial effusions reverse this gradient and may therefore interfere with cartilage nutrition (Jayson and others, 1970).

High intra-articular pressures and their ill-effects will decrease if the volume of effusion in the knee is reduced. Synovial cysts therefore appear to have a protective value in rheumatoid arthritis of the knee.

\section{Summary}

A series of 36 knees in 24 patients affected by rheumatoid arthritis were examined. The knees had been involved for at least 5 years. Geodes, osteoporosis, osteophytes, surface erosions, and loss of joint space were quantified from $x$ rays and summed to produce a 'total knee score'. Arthrograms were performed on all these joints and in all but one a popliteal cyst was demonstrated. Many of these cysts had not been detected on clinical examination. The cyst sizes were measured. The 'total knee scores' were inversely related to the sizes of the synovial cysts. Geodes also tended to be inversely related to synovial cysts. The results are compatible with the hypothesis that synovial cysts have a protective value in rheumatoid knees.

We wish to thank Dr. J. A. Cosh, and Dr. G. D. Kersley for allowing us to examine their patients, Mr. J. Gray, our radiographer, for his help with this project, and Mrs. E. Collins for the statistical analysis. M. I. V. J. is in receipt of a research grant from the Medical Research Council.

\section{References}

Billroth, T. (1875) ‘General Surgical Pathology and Therapeutics', trans. C. E. Hackley. Lewis, London Burleson, R. J., Bickel, W. H., AND DAhlin, D. C. (1956) J. Bone Jt Surg., 38A, 1265 (Popliteal cyst)

BYwATERS, E. G. L. (1964) 'The hand' in 'Radiological Aspects of Rheumatoid Arthritis'. Excerpta medica International Congress Series, No. 61, p. 43

Castillo, B. A., El Sallab, R. A., and Scott, J. T. (1965) Ann. rheum. Dis., 24, 522 (Physical activity, cystic erosions and osteoporosis in rheumatoid arthritis)

Cruickshank, B., Macleod, J. G., and Shearer, W. S. (1954) J. Fac. Radiol. (Lond.), 5, 218 (Subarticular pseudocysts in rheumatoid arthritis) 
Drxon, A. St. J. (1966) 'Rheumatic diorders', in 'Progress in Clinical Medicine', ed. R. Daley, and H. Miller, 5th ed., p. 428. Churchill, London

Eкholm, R., AND Inglemark, B. E. (1952) Acta Soc. Med. upsalien, 57, 39 (Functional thickness variations of human articular cartilage)

Fletcher, D. E., AND Rowley, K. A. (1952) Brit. J. Radiol., 25, 282 (The radiological features of rheumatoid arthritis)

FreUND, E. (1940) Edinb. med. J., 47, 192 (The pathological significance of intra-articular pressure)

Fullerton, A. (1916) Brit. J. Surg., 4, 191 (The surgical anatomy of the synovial membrane of the knee joint)

Greenwald, A. S., AND Haynes, D. W. (1969) J. Bone Jt Surg., 51B, 747 (A pathway for nutrients from the medullary cavity to the articular cartilage of the human femoral head)

GristinA, A. G., AND Wilson, P. D. (1964) Arch. Surg., 88, 357 (Popliteal cysts in adults and children)

HAll, A. P., AND Scott, J. T. (1966) Ann. rheum. Dis., 25, 32 (Synovial cysts and rupture of the knee joint in rheumatoid arthritis. An arthrographic study)

HARVEY, J. P., AND CoRCos, J. (1960) Arthr. and Rheum., 3, 218 (Large cysts in lower leg originating in the knee occurring in patients with rheumatoid arthritis)

INGLEMARK, B. E., AND EKHOLM, R. (1948) Upsala Läk. -Fören. Förh., 53, 61 (A study on variations in thickness of articular cartilage in association with rest and periodical load. An experimental investigation on rabbits)

- , AND SÄÄF, J. (1948) Acta orthop. scand., 17, 303 (Über die Ernährung des Gelenkknorpels und die Bildung der Gelenkflüssigkeit unter verschiedenen funktionellen Verhältnissen)

Jayson, M. I. V., AND Dixon, A. ST. J. (1970a) Ann. rheum. Dis., 29, 401 (Intra-articular pressure in rheumatoid arthritis of the knee. Part III)

- - - (1970b) Ibid., 29, 415 (Valvular mechanisms in juxta-articular cysts)

-, RuBenstein, D., AND Dixon, A. St. J. (1970) Ibid., 29, 496 (Intra-articular pressure and rheumatoid geodes)

-, Swannell, A. J., KirK, J. A., And Dixon, A. St. J. (1969) Ann. phys. Med., 10, 175 (Acute joint rupture)

Kersley, G. D., Ross, F. G. M., Fowles, S. J., AND Johnson, C. (1964) Ann. rheum. Dis., 23, 280 (Tomography in arthritis of the small joints)

KogStad, O. (1965) Acta rheum. scand., 11, 194 (Baker's cyst)

LEWIN, P. (1952) 'The Knee and Related Structures'. Kimpton, London

LITwIN, S. D., Lister, J., AND RotsteIN, J. (1964) N.Y. St. J. Med., 64, 2107 (Bilateral popliteal cysts in a patient with rheumatoid arthritis)

Meyerding, H. W., and Van Demark, R. E. (1943) J. Amer. med. Ass. 122, 858 (Posterior hernia of the knee)

Palmer, D. G. (1969) Ann. intern. Med., 70, 61 (Synovial cysts in rheumatoid disease)

Perri, J. A., Rodman, G. P., ANd Mankin, H. J. (1968) J. Bone Jt Surg., 50A, 709 (Giant synovial cysts of the calf in patients with rheumatoid arthritis)

Ropes, M. W., Bennett, G. A., Cobb, S., Jacox, R., And Jessar, R. A. (1959) Ann. rheum. Dis., 18, 49 (Diagnostic criteria for rheumatoid arthritis)

SoIlA, P. (1963) Acta rheum. scand., 9, 231 (The causal relations of rheumatoid disintegration of juxta-articular bone trabeculae)

Wilson, P. D., Eyre-Brook, A. L., AND Francis, J. D. (1938) J. Bone Jt Surg., 20, 963 (A clinical and anatomical study of the semimembranosus bursa in relation to popliteal cysts) 